\title{
Un nuevo híbrido natural de Dracula (Orchidaceae: Pleurothallidinae) del suroccidente de Ecuador
}

\section{A new natural hybrid of Dracula (Orchidaceae: Pleurothallidinae) from southwestern Ecuador}

\author{
Bosco Javier Zambrano ${ }^{1 *}$ y Rodolfo Solano-Gómez ${ }^{2}$ \\ ${ }^{1}$ Centro de Tenencia Orquiecuador. Sucre y Garcia Moreno, esquina frente al Parque central, 071050 Piñas, El Oro, Ecuador. \\ ${ }^{2}$ Centro Interdisciplinario de Investigación para el Desarrollo Integral Regional, Unidad Oaxaca, Instituto Politécnico Nacional. Hornos 1003,71230 \\ Santa Cruz Xoxocotlán, Oaxaca, México. \\ *Correspondencia: bosco_escorpion@hotmail.com
}

\begin{abstract}
Resumen. Se describe e ilustra un nuevo híbrido natural de Dracula de Ecuador, Dracula x pinasensis, el cual fue recientemente descubierto en el bosque húmedo de los Andes del suroccidente de Ecuador. El nuevo híbrido es comparado con Dracula mantissa, D. mopsus y D. ophioceps de Sudamérica, así como D. pusilla de Centroamérica, orquídeas con las cuales está más relacionada. Se señala a D. mopsus y D. ophioceps como los progenitores putativos de este híbrido natural.

Palabras clave: bosque húmedo andino, Dracula mantissa, D. mopsus, D. ophioceps, D. x pinasensis, D. pusilla, Ecuador.

Abstract. A new natural hybrid of Dracula from Ecuador is described and illustrated, Dracula $\mathrm{x}$ pinasensis, which was recently discovered in the Andean wet forest from Southwestern Ecuador. The new hybrid is compared with the South American D. mantissa, D. mopsus, and D. ophioceps, as well the Central American D. pusilla, the closest allies. D. mopsus and D. ophioceps are pointed out as the putative parents of this natural hybrid.
\end{abstract}

Key words: Andean wet forest, Dracula mantissa, D. mopsus, D. ophioceps, D. x pinasensis, D. pusilla, Ecuador.

\section{Introducción}

Dracula Luer es un género de orquídeas principalmente epífitas, aunque a veces llegan a ser terrestres, que habitan en los bosques húmedos y de neblina del neotrópico; pertenece a la subtribu Pleurothallidinae y está muy relacionado con Masdevallia Ruiz et Pav. y Porroglossum Schltr. (Luer, 1978, 1986, 1993; Pridgeon et al., 2001; Calderón y Farfán, 2003; Pridgeon, 2005). Excluyendo a $D$. xenos Luer et Escobar, que parece ser un híbrido entre Dracula y Masdevallia, Dracula sería un grupo monofilético cuyas especies no presentan serios problemas para su delimitación (Pridgeon, 2005; Pridgeon et al., 2001), siendo muchas de ellas muy conocidas y apreciadas en cultivo. Actualmente se reconocen casi 120 especies en el género distribuidas desde el sureste de México hasta Perú, pero con una mayor concentración en los bosques andinos de Colombia y Ecuador, donde se conocen 72 y 56 especies, respectivamente (Luer, 1993; Calderón y Farfán, 2003; Viveros y Higgins, 2007; Pupulin et al., 2009).

Recibido: 28 marzo 2010; aceptado: 12 enero 2011
Recientemente en la colección de Orquiecuador florecieron plantas de Dracula de la provincia El Oro, superficialmente similares a algunas especies del género que crecen en los Andes de Ecuador y Colombia, como D. mopsus (Lehm. et Kranzl.) Luer, endémica de Ecuador y con la cual es simpátrica en la misma provincia, así como D. mantissa Luer et Escobar y D. ophioceps Luer et Escobar de Colombia. Sin embargo, al revisar el material cultivado y compararlo con la literatura, ilustraciones y fotografías del género, se notaron varios rasgos que lo hacían diferente de estas orquídeas. Otra especie con la que parecía muy similar es $D$. pusilla (Rolfe) Luer, una orquídea de Centroamérica registrada de México hasta Panamá, pero no en Colombia y Ecuador (Luer, 1978, 1993; Calderón y Farfán, 2003). Sin embargo, también se encontraron diferencias entre esta planta y el material de El Oro y se descartó que los ejemplares correspondan a alguna especie conocida de Dracula. Como la planta recientemente colectada en esta provincia es muy similar y simpátrica con $D$. mopsus, se considera como un híbrido natural, para la cual uno de sus progenitores putativos sería esta especie, por lo que se describe e ilustra aquí a partir de material vivo y herborizado. Los ejemplares de respaldo se depositaron en el Herbario de la Facultad de Ciencias 


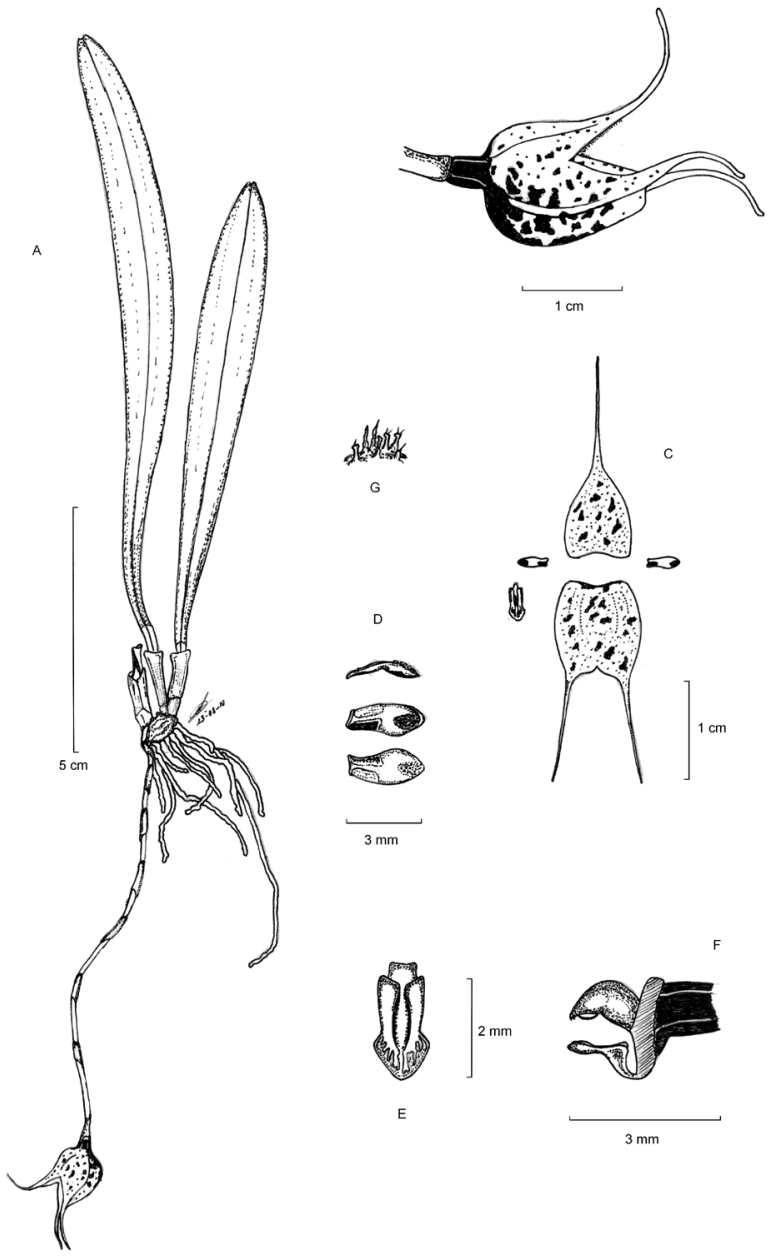

Figura 1. Dracula x pinasensis, dibujo de J. Zambrano basado en el holotipo. A, hábito; B, vista lateral de la flor; C, disección floral; D, pétalos en diferentes vistas; E, labelo en vista frontal; F, labelo y columna en vista lateral; $\mathrm{G}$, detalle de los pelos en el sépalo.

Naturales de la Universidad de Guayaquil (GUAY) y en la colección particular de Orquiecuador (J. Zambrano).

\section{Descripción}

Dracula $\mathbf{x}$ pinasensis Zambrano et $\mathrm{R}$. Solano hybr. nat. nov., Figs. 1 y 2. Tipo: ECUADOR: Provincia El Oro: Piñas, Sector Buenos Aires, km 4.94 del Cantón Piñas vía a Machala, $1200 \mathrm{~m}$ elev., 18.II.2007, cultivado en Orquiecuador, Zambrano B. 30 (Holotipo: GUAY; isotipo: Herbario J. Zambrano, in spirit).

Species haec Draculae mopso persimilis, sed folio erecto, coriaceo, oblongo-lanceolato, ovario longo, laevi, cylindrico, rubello, sepalis luridis, intus sparsim pubescentibus, caudis curvatis, petalis phoeniceo-signatis,

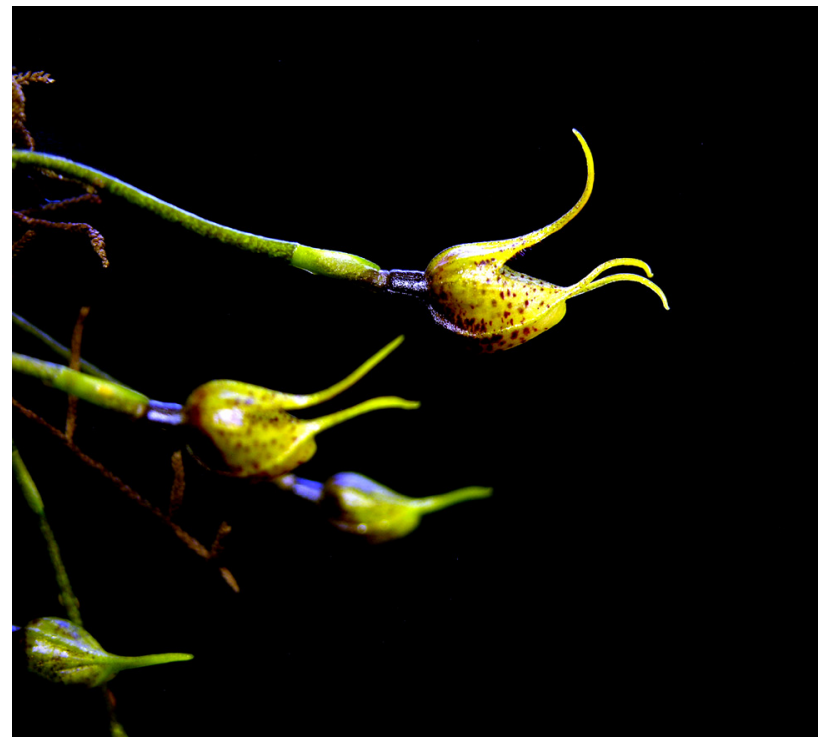

Figura 2. Dracula x pinasensis, foto de J. Zambrano.

obovatis-spathulata, ad apicem acutis, epichilio obovatis, hypochilio margine erecto differt.

Hierba mediana, epifita, erecta, densamente cespitosa, hasta $15 \mathrm{~cm}$ de alto. Raíces delgadas, flexuosas, blanquecinas. Tallos monófilos, cortos, cilíndricos, de $1.5-2 \mathrm{~cm}$ de largo, formados por 2 entrenudos, cubiertos totalmente por vainas tubulares, traslapadas; con un anillo engrosado en la mitad del entrenudo superior. Hoja erecta, ligeramente coriácea, carinada, oblanceolada, obtusa, bidentada y mucronada en el ápice, $10-12 \mathrm{~cm}$ de largo, $1-1.2 \mathrm{~cm}$ de ancho, gradualmente atenuada hacia la base para formar un pecíolo indistinto y conduplicado. Inflorescencia del anillo del tallo, descendente, de una sola flor dirigida hacia abajo; pedúnculo cilíndrico, $6-8.5 \mathrm{~cm}$ de largo, con 5-7 brácteas cortamente tubulares, similares a las florales. Brácteas florales cortamente tubulares, oblicuas en el ápice, estrechas, membranáceas, $6 \mathrm{~mm}$ de largo. Ovario robusto, liso, rojo-púrpura oscuro, $3 \mathrm{~mm}$ de largo, articulado a un pedicelo terete de $5-7 \mathrm{~mm}$ de largo y 1-1.5 mm de grosor. Flores pequeñas, tubular-globosas, ligeramente comprimidas lateralmente, los sépalos color amarillo, punteados de rojo-púrpura, pubescentes, los pelos escasamente ramificados, con caudas teretes bien desarrolladas, recurvadas y amarillas, los pétalos amarillo-marfil con manchas rojo-púrpura, el labelo amarillo claro, callo manchado de rosa, la columna y la antera amarillas. Sépalo dorsal largamente caudado, unido a los laterales en un tercio de su longitud, cóncavo, la lámina ovada, $9 \times 6 \mathrm{~mm}$, la cauda $11 \times 1 \mathrm{~mm}$. Sépalos laterales connatos entre sí casi en la mitad de su longitud para formar una lámina cimbiforme, oblonga-elíptica y pro- 
fundamente bipartida al extenderse, $9 \times 9 \mathrm{~mm}$, carinada en la superficie externa a lo largo de las nervaduras, la cauda de $11 \times 1 \mathrm{~mm}$. Pétalos erectos, paralelos a la columna, cartilaginosos, ligeramente oblícuos, ovado-espatulados, obtusos, bivalvados y reflexos en el ápice, carinados a lo largo de la nervadura, papiloso en el margen inferior, $3 \times$ $1 \mathrm{~mm}$. Labelo articulado al pie de columna, ascendente en la base y reflexo hacia el ápice, dividido en hipoquilo y epiquilo, panduriforme, carnoso, longitudinalmente canaliculado, $2.3 \times 1.2 \mathrm{~mm}$; hipoquilo más angosto que el epiquilo, oblongo, los márgenes erectos pareciendo formar lóbulos oscuros, $1 \times 1.2 \mathrm{~mm}$; epiquilo calceolado, obovado, obtuso, los márgenes involutos, proyectando hacia el centro 7 quillas que rodean la parte superior del canal del hipoquilo, $1.3 \times 1 \mathrm{~mm}$. Columna corta, robusta, semiterete, incurvada en el ápice, $2.4 \mathrm{~mm}$ de largo, 1.5 $\mathrm{mm}$ de ancho, con pie conspicuo. Estigma ventral, excavado. Antera ventral, incurvada en el ápice. Polinario con 2 polinios obovoides, lateralemente comprimidos.

Distribución y hábitat. Hasta ahora este híbrido es endémico de Ecuador, donde sólo ha sido registrado en las montañas del suroccidente, en la provincia El Oro, entre 1200 y $1500 \mathrm{~m}$ de elevación. Crece como epífita en el bosque siempreverde piemontano y bosque semideciduo montano, donde las neblinas son frecuentes durante todo el año, pero especialmente en el verano. Generalmente, las plantas crecen sobre ramas o troncos encima de una capa gruesa de musgo o materia orgánica.

Fenología. Florece entre febrero y agosto.

Estado de conservación. No evaluado. Las poblaciones conocidas de este híbrido se encuentran en remanentes de bosque de zonas perturbadas por la actividad agrícola, ganadera y tala de árboles que no se encuentran dentro de áreas naturales protegidas.

Etimología. El nombre del híbrido es en alusión a Piñas, la localidad donde fue descubierto.

Ejemplares adicionales. ECUADOR: Piñas, Cordillera de Curitejo, km 3.46 del Cantón Piñas, vía a Capiro, 1500 m elev., 13.III.2007, cultivado en Orquiecuador, Zambrano B. 50 (Herbario J. Zambrano); sector San Jacinto, $1400 \mathrm{~m}$ elev., 20.VIII.2007, cultivado en Orquiecuador, Zambrano B. 120 (Herbario J. Zambrano).

Comentarios taxonómicos. Dracula x pinasensis, es muy similar a D. mopsus, especie endémica del Ecuador con la cual llega a ser simpátrica; sin embargo ésta difiere por sus plantas más robustas, hojas más anchas $(1.5-2.5 \mathrm{~cm} v s$. 1-1.2 cm), brácteas florales más largas $(8-10 \mathrm{~mm}$ de largo vs. $6 \mathrm{~mm}$ de largo), ovario con crestas longitudinales (vs. ovario liso), sépalos con pelos estrellados ( $v s$. pelos escasamente ramificados), las caudas rectas de 5-7 $\mathrm{mm}$ de largo (vs. recurvadas de $11 \mathrm{~mm}$ ), los pétalos oblongo-espatulados y redondeados (vs. obovado-espatulados y obtusos) y labelo con epiquilo orbicular y redondeado ( $v s$. epiquilo obovado y obtuso) (Luer, 1993).

Dracula ophioceps, de Colombia y D. mantissa, de Ecuador y Colombia (Luer, 1993) son también especies similares. La primera se diferencia por sus hojas más anchas (1.5-2 cm vs. 1-1.2 cm), flores amarillo-pálido sin puntuaciones (vs. flores amarillas con manchas rojo púrpura, más pronunciada en la base de la flor), pedúnculo más largo $(15-18 \mathrm{~cm}$ vs. 6-8.5 cm), brácteas florales más largas (7-10 mm vs. $6 \mathrm{~mm}$ de largo), ovario de 4-5 $\mathrm{mm}$ de largo y provisto de pequeñas crestas (vs. ovario de $3 \mathrm{~mm}$ de largo y liso), flores más grandes, sépalos reflexos arriba de la mitad ( $v s$. cóncavos), con caudas rectas (vs. caudas recurvadas), sépalos con pelos simples ( $v s$. pelos escasamente ramificados), pétalos oblongos y redondeados (vs. pétalos obovado-espatulados y obtusos), labelo con el epiquilo redondeado (vs. epiquilo obtuso) y columna de $4 \mathrm{~mm}$ de largo (vs. $2.4 \mathrm{~mm}$ de largo). Por su parte, D. mantissa, es diferente por sus hojas más largas y anchas, inflorescencia horizontal ( $v s$. descendente), ovario provisto de crestas longitudinales (vs. liso), flores relativamente más pequeñas, pétalos oblongos y constreñidos cerca de la mitad (vs. obovado-espatulados y ensanchados arriba de la mitad), labelo con epiquilo casi tan ancho como el hipoquilo (vs. epiquilo más ancho que el hipoquilo) y antera cubierta completamente por el clinandrio ( $v s$. antera con el ápice proyectado encima del clinandrio).

Finalmente, Dracula pusilla, que se distribuye desde Oaxaca y Chiapas, en México, hasta Panamá (Soto-Arenas, 1992; Luer, 1993) muestra similitudes con el híbrido aquí descrito. Esta especie se diferencia por tener sépalos frecuentemente con pelos ramificados, caudas rectas y proporcionalmente más largas, pétalos oblongos y redondeados, epiquilo del labelo reniforme, redondeado y menos ancho que el hipoquilo (Soto-Arenas, 1992). Es probable que el reporte de D. pusilla para Ecuador (Luer, 1978) corresponda a un ejemplar del híbrido que aquí se describe, o bien, a uno de D. mantissa o D. mopsus que fuera mal determinado.

Ya se mencionó que Dracula x pinasensis, es simpátrica y muy similar a D. mopsus en la provincia de El Oro, por lo que esta especie podría ser un progenitor putativo. Dracula ophioceps, que se conoce del suroccidente de Colombia (Luer, 1993; Calderón y Farfán, 2003; Viveros y Higgins, 2007), es también muy similar y podría asimismo ser otro posible progenitor, pero ésta no ha sido registrada hasta ahora en Ecuador (Pupulin et al., 2009).

\section{Agradecimientos}

A Willibald Königer por la corrección de la diagnosis en latín. A los revisores anónimos del manuscrito. 


\section{Literatura citada}

Calderón, E. y J. C. Farfán. 2003. Especies de los géneros Dracula y Masdevallia (Orchidaceae) en Colombia. Biota Colombiana 4:187-201.

Luer, C. A. 1978. Dracula, a new genus in the Pleurothallidinae. Selbyana 2:190-198.

Luer, C. A. 1986. Icones Pleurothallidinarum I. Systematics of the Pleurothallidinae. Monographs in Systematic Botanic from Missouri Botanical Garden 15:23-25.

Luer, C. A. 1993. Icones Pleurothallidinarum X. Systematics of Dracula. Monographs in Systematic Botanic from Missouri Botanical Garden 46:1-244.

Pridgeon, A. M. 2005. Dracula (tratamiento genérico). In Genera
Orchidacearum, vol. 4: Epidendroideae (part one), A. M. Pridgeon, P. J. Cribb, M. W. Chase y F. N. Rasmussen (eds.). Oxford University Press, New York. p. 349-351.

Pridgeon, A. M., R. Solano y M. W. Chase. 2001. Phylogenetic relationships in subtribe Pleurothallidinae (Orchidaceae): combined evidence from nuclear plastid nuclear DNA sequences. American Journal of Botany 88:2286-2308.

Pupulin, F., H. Medina y G. Merino. 2009. Draculas del Ecuador del Ecuador. Centro de Investigación en Orquídeas de los Andes Ángel Andreetta, Quito, Ecuador. p. 79.

Soto-Arenas, M. A. 1992. Dracula pusilla, an addition to the Mexican orchid flora. Orquídea [México] 12:277-280.

Viveros, P. y W. E. Higgins. 2007. Checklist of Pleurothallidinae from Colombia. Selbyana 281:13-90. 